\title{
Modified GPS/Pseudolite Navigation Message
}

\author{
Jacek Rapinski, Slawomir Cellmer and Zofia Rzepecka \\ (University of Warmia and Mazury in Olsztyn, Poland) \\ (E-mail: jacek.rapinski@gmail.com)
}

\begin{abstract}
One of the issues regarding integrated GPS/pseudolite measurements is how to deliver a pseudolite's position to a receiver or to post-processing software and how to manage it. This paper presents a proposed solution to this problem. The standard navigation message is modified in such way that without changing receivers (or post-processing software), the calculated position of a transmitter is fixed at a pseudolite's known position. The formulae for modification of standard Ephemeris Data are also derived. This algorithm can be implemented in a transmitter's firmware or a navigation data file can be modified for postprocessing.
\end{abstract}

\section{KEY WORDS}

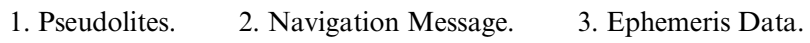

First published online: 23 March 2012.

1. INTRODUCTION. Pseudolites can be used in practice for three main purposes depending on the operational conditions and the user's requirements (Lee et al., 2004; Wang, 2002):

- To strengthen the geometry of the ranging intersection: when very high accuracy is required, as in deformation monitoring,

- To improve the reliability of a satellite solution: when there are very strict demands concerning the system used, as in aircraft landing,

- To provide the possibility of satellite-like positioning indoors: as in positioning in mines, tunnels, large buildings, etc.

There are a few things to be considered before including a pseudolite in a positioning system. Items of major importance (Cobb, 1997; Wang et al., 2005) are:

- Near/far problem.

- Carrier phase noise.

- Multipath.

- Dealing with the navigation message.

- Linearization of observations.

- Modelling of the troposphere. 
Some of these issues can be resolved by software modification and some require modification of hardware or both software and hardware. The processing of GPS/ pseudolite integrated observations requires a slightly different approach than that taken to standard GPS observables. Factors which need to be taken into consideration in the software are:

- Different troposphere modelling.

- Lack of ionosphere delay in pseudolite observations.

- The necessity of using more than one term of a Taylor series expansion during linearization of observation equations (Cellmer and Rapinski, 2010), a different method of providing a transmitter's position.

The last point is the main topic of this paper. The method of designing a pseudolite's navigation message is one of the major issues in integrated GPS-pseudolite surveys. The standard algorithm for determination of a satellite position implemented in the receivers does not allow the use of a pseudolite signal. The satellite position is calculated on the basis of Kepplerian orbit parameters, which are not applicable for the pseudolite. In the case of a pseudolite, its position needs to be delivered as fixed coordinates. One solution would be to provide the pseudolite's position by putting the coordinates in spare fields of a navigation data message. This approach would require a modification in a receiver's firmware.

Standard receivers do not use spare fields, so it would not be able to read a pseudolite's position. Another solution would be to elaborate a method which would provide a pseudolite's position without modifying a receiver's firmware. Such a method would be an optimal approach. This paper presents a proposed solution to this problem.

2. SAtellite position CAlCulation Algorithm. To calculate the user's position, each receiver needs to calculate the position of each satellite. It is usually done on the basis of a navigation message sent by a satellite. According to Strang and Borre (1997), the position of each satellite is calculated using the algorithm presented below:

$$
\mathrm{a}=\sqrt{\mathrm{a}}^{2}
$$

where ' $a$ ' is the semi-major axis of the satellite orbit, and:

$$
\mathrm{t}_{\mathrm{k}}=\mathrm{t}-\mathrm{t}_{\mathrm{oe}},
$$

where:

$t_{k}$ is the time elapsed since $t_{o e}$.

' $\mathrm{t}$ ' is the transmit time.

$t_{\mathrm{oe}}$ is the ephemeris epoch.

$$
\mathrm{M}=\mu_{0}+\left(\sqrt{\frac{\mathrm{GM}}{\mathrm{a}^{3}}}+\Delta \mathrm{n}\right) \mathrm{t}_{\mathrm{k}},
$$

where:

' $\mathrm{M}$ ' is the mean anomaly at time $\mathrm{t}_{\mathrm{k}}$ 
$\mathrm{GM}=3 \cdot 986005 \cdot 10^{14} \mathrm{~m}^{3} / \mathrm{s}^{2}$.

$\Delta \mathrm{n}$ and $\mu_{0}$ are obtained from ephemeris data.

Next, the eccentric anomaly ' $\mathrm{E}$ ' is calculated through iteration as:

$$
\mathrm{E}=\mathrm{M}+\mathrm{e}_{\mathrm{cc}} \sin \mathrm{E},
$$

where:

$\mathrm{e}_{\mathrm{cc}}$ is the eccentricity of the satellite orbit.

In the first iteration $\mathrm{E}=\mathrm{M}$ is assumed.

The true anomaly ' $\mathrm{v}$ ' can be calculated using the following equation:

$$
\mathrm{v}=\left(\frac{\sqrt{1-\mathrm{e}_{\mathrm{cc}}^{2}} \sin \mathrm{E}}{\cos \mathrm{E}-\mathrm{e}_{\mathrm{cc}}}\right)
$$

A new variable $\Phi$ is introduced and its value is computed using $\omega$ from the ephemeris data:

$$
\Phi=\mathrm{v}+\omega,
$$

The argument of perigee is computed from:

$$
\mathrm{u}=\Phi+\mathrm{C}_{\mathrm{uc}} \cos 2 \Phi+\mathrm{C}_{\mathrm{us}} \sin 2 \Phi,
$$

where $\mathrm{C}_{\mathrm{uc}}$ and $\mathrm{C}_{\mathrm{us}}$ are obtained from ephemeris data.

Radial distance reads:

$$
\mathrm{r}=\mathrm{a}\left(1-\mathrm{e}_{\mathrm{cc}} \cos \mathrm{E}\right)+\mathrm{C}_{\mathrm{rc}} \cos 2 \Phi+\mathrm{C}_{\mathrm{rs}} \sin 2 \Phi,
$$

where $\mathrm{C}_{\mathrm{rc}}$ and $\mathrm{C}_{\mathrm{rs}}$ are also obtained from ephemeris data.

Inclination is calculated from:

$$
\mathrm{i}=\mathrm{i}_{0}+\mathrm{i}_{\text {dot }} \mathrm{t}_{\mathrm{k}}+\mathrm{C}_{\mathrm{ic}} \cos 2 \Phi+\mathrm{C}_{\mathrm{is}} \sin 2 \Phi,
$$

Right ascension of ascending node:

$$
\Omega=\Omega_{0}+\left(\dot{\Omega}-\dot{\Omega}_{\mathrm{e}}\right) \mathrm{t}_{\mathrm{k}}-\dot{\Omega}_{\mathrm{e}} \mathrm{t}_{\mathrm{oe}},
$$

Denoting:

$$
\mathrm{x}_{1}=\mathrm{r} \cos (\mathrm{u})
$$

and:

$$
\mathrm{y}_{1}=\mathrm{r} \sin (\mathrm{u}),
$$

The position of a satellite can be expressed in the form of the following vector:

$$
\left[\begin{array}{l}
\mathrm{x} \\
\mathrm{y} \\
\mathrm{z}
\end{array}\right]=\left[\begin{array}{c}
\mathrm{x}_{1} \cos \Omega-\mathrm{y}_{1} \cos (\mathrm{i}) \sin \Omega \\
\mathrm{x}_{1} \sin \Omega+\mathrm{y}_{1} \cos (\mathrm{i}) \cos \Omega \\
\mathrm{y}_{1} \sin (\mathrm{i})
\end{array}\right],
$$

Parameters: $\mu_{0}, \Delta \mathrm{n}, \mathrm{e}, \sqrt{a}, \Omega_{0}, \mathrm{i}_{0}, \omega, \dot{\Omega}, \mathrm{i}_{\mathrm{dot}}, \mathrm{C}_{\mathrm{uc}}, \mathrm{C}_{\mathrm{us}}, \mathrm{C}_{\mathrm{rc}}, \mathrm{C}_{\mathrm{rs}}, \mathrm{C}_{\mathrm{ic}}, \mathrm{C}_{\mathrm{is}}, \mathrm{t}_{\mathrm{oe}}$ are broadcast in the ephemerides. 
Table 1: Ephemeris data modification.

\begin{tabular}{lc}
\hline Parameter & Value \\
\hline $\mathrm{C}_{\mathrm{uc}}, \mathrm{C}_{\mathrm{us}}$ & 0 \\
$\mathrm{e}_{\mathrm{cc}}$ & \\
$\mathrm{t}_{\mathrm{oe}}$ & \\
$\mathrm{i}_{\mathrm{dot}}, \mathrm{C}_{\mathrm{ic}}, \mathrm{C}_{\mathrm{is}}$ & $\mathrm{a} \tan \left(-\frac{\mathrm{x}}{\mathrm{y}}\right)$ \\
$\mathrm{C}_{\mathrm{rc}}, \mathrm{C}_{\mathrm{rs}}, \mathrm{e}_{\mathrm{cc}}$ & $\mathrm{a} \tan \left(-\frac{z \sin \Omega}{\mathrm{x}}\right)$ \\
$\Omega_{0}$ & $\frac{\mathrm{z}}{\sin (\mathrm{i})}$ \\
$\mathrm{i}_{0}$ & $7 \cdot 2921151467 \cdot 10^{-5}$ \\
$\mathrm{a}$ & $\frac{\pi}{2}$ \\
$\dot{\Omega}$ & $-\sqrt{\frac{\mathrm{GM}}{\mathrm{a}^{3}}}$ \\
$\omega$ &
\end{tabular}

3. MODIFICATION IN THE EPHEMERIS DATA. The position of a pseudolite on the surface of Earth means that there are no valid orbit parameters to describe it (the geostationary orbit at any longitude, latitude and height close to the surface is impossible from a Kepplerian orbit point of view). However, since the algorithm for satellite position computation is well-known, it is possible to express any coordinates using only broadcast ephemerides' data. In this way we can 'cheat' the receiver to use the pseudolite just like any other satellite without any modifications. The main goal of the algorithm presented below is to make the resulting coordinates independent from time and fix them at required values.

Let us denote a known pseudolite's coordinates as X, Y, Z in an Earth-fixed, Earthcentred coordinate system. All three coordinates depend on $\Omega, \mathrm{i}, \mathrm{x}_{1}, \mathrm{y}_{1}$ where both ' $\mathrm{x}_{1}$ ' and ' $y_{1}$ ' depend on ' $u$ ' and ' $r$ '. First, let's make the assumption that $u=\frac{\pi}{2}$ and substitute Equations (11) and (12) into Equation (13):

$$
\left[\begin{array}{l}
x \\
y \\
z
\end{array}\right]=\left[\begin{array}{c}
-r \cos (i) \sin \Omega \\
r \cos (i) \cos \Omega \\
r \sin (i)
\end{array}\right],
$$

where ' $\mathrm{x}, \mathrm{y}, \mathrm{z}$ ' are known pseudolite coordinates.

For the ' $u$ ' parameter to be set to $\frac{\pi}{2}$ the following conditions must be fulfilled:

- In Equation 7 terms $\mathrm{C}_{\mathrm{uc}}, \mathrm{C}_{\mathrm{us}}$ must be set to 0 .

- In Equation 6 parameter v must be set to 0 .

- Parameter $\omega$ must be set to $\frac{\pi}{2}$.

- For the 'v' to be 0 parameter $\mathrm{e}_{\mathrm{cc}}$ must be set to 0 and parameter $\Delta \mathrm{n}$ must be set to:

$$
\Delta \mathrm{n}=-\sqrt{\frac{\mathrm{GM}}{\mathrm{a}^{3}}},
$$

- Parameter a in the above equation must be set to $r$. 
Table 2: Pseudolite's coordinates.

\begin{tabular}{lcc}
\hline$X$ & $Y$ & $Z$ \\
\hline $3882469 \cdot 859$ & $1211762 \cdot 869$ & $4896966 \cdot 245$ \\
\hline
\end{tabular}

Table 3: Example of ephemeris data modification.

\begin{tabular}{lcc}
\hline Parameter & Original value & Modified Value \\
\hline $\mathrm{C}_{\mathrm{uc}}$ & $4 \cdot 1910 \cdot 10^{-6}$ & 0 \\
$\mathrm{C}_{\mathrm{us}}$ & $1 \cdot 3931 \cdot 10^{-5}$ & 0 \\
$\mathrm{e}_{\mathrm{cc}}$ & $6 \cdot 4347 \cdot 10^{-3}$ & 0 \\
$\mathrm{C}_{\mathrm{rc}}$ & $1 \cdot 1697 \cdot 10^{2}$ & 0 \\
$\mathrm{C}_{\mathrm{rs}}$ & $8 \cdot 2125 \cdot 10^{1}$ & 0 \\
$\mathrm{t}_{\mathrm{oe}}$ & $3 \cdot 6000 \cdot 10^{5}$ & 0 \\
$\mathrm{i}_{\mathrm{dot}}$ & $-4 \cdot 8573 \cdot 10^{-11}$ & 0 \\
$\mathrm{C}_{\mathrm{ic}}$ & $-4 \cdot 6566 \cdot 10^{-8}$ & 0 \\
$\mathrm{C}_{\mathrm{is}}$ & $-1 \cdot 4156 \cdot 10^{-7}$ & $\frac{\pi}{2}$ \\
$\dot{\Omega}$ & $-7 \cdot 6953 \cdot 10^{-9}$ & $7 \cdot 2921151467 \cdot 10^{-5}$ \\
$\omega$ & $2 \cdot 9465$ & $2523 \cdot 03518583443065$ \\
$\mathrm{a}$ & $5 \cdot 1536 \cdot 10^{3}$ & $0 \cdot 87770253122711661$ \\
$\mathrm{i}_{0}$ & $9 \cdot 7031 \cdot 10^{-1}$ & $-1 \cdot 26826557970229570$ \\
$\Omega_{0}$ & $1 \cdot 9946 \cdot 10^{-1}$ & $-0 \cdot 00124307976808151$ \\
$\Delta \mathrm{n}$ & $3 \cdot 8866 \cdot 10^{-9}$ & $3882469 \cdot 859$ \\
$\mathrm{Results}$ & & $1211762 \cdot 869$ \\
$\mathrm{X}$ & $26717454 \cdot 572$ & $4896966 \cdot 245$ \\
$\mathrm{Y}$ & $723406 \cdot 652$ & \\
$\mathrm{Z}$ & $37418 \cdot 567$ & \\
\hline
\end{tabular}

From the set of Equation(s) 14, the values of $\Omega$, 'I' and 'r' can be derived:

$$
\begin{gathered}
\Omega=\Omega_{0}=\mathrm{a} \tan \left(-\frac{\mathrm{x}}{\mathrm{y}}\right), \\
\mathrm{i}=\mathrm{i}_{0}=\mathrm{a} \tan \left(-\frac{\mathrm{z} \sin \Omega}{\mathrm{x}}\right), \\
\mathrm{r}=\frac{\mathrm{z}}{\sin (\mathrm{i})},
\end{gathered}
$$

To make $\Omega$ independent from time, the parameter $\mathrm{t}_{\mathrm{oe}}$ must be equal to 0 and $\dot{\Omega}$ must be equal to $7 \cdot 2921151467 \cdot 10^{-5}$, which is equal to the Earth's rotation rate. Similarly, to make ' $i$ ' independent from time, the parameters $i_{\mathrm{dot}}, \mathrm{C}_{\mathrm{ic}}, \mathrm{C}_{\mathrm{is}}$ must be set to 0 . The value from Equation 16 for $\Omega_{0}$ and the value from Equation 16 for $\mathrm{i}_{0}$ must be substituted in the ephemeris data. Parameter ' $r$ ' must be treated in an analogous way. $\mathrm{C}_{\mathrm{rc}}, \mathrm{C}_{\mathrm{rs}}, \mathrm{e}_{\mathrm{cc}}$ must be equal to 0 . Then $\mathrm{r}=\mathrm{a}$ which can be substituted into the ephemeris data. The summary of modifications made to the ephemeris data to obtain the pseudolite location is presented in Table 1 . 
4. EXAMPLE. In order to test the developed algorithm, real data was used. One of the possible ways of dealing with pseudolite signal identification is to use the Pseudorandom Noise (PRN) code number of a satellite that is not in view (Bond, 2007). Table 3 presents standard and modified parameters along with resulting coordinates. The true pseudolite coordinates are presented in Table 2. The calculations were made for epoch 700 and PRN23. From Table 3 we can see that the final position computed on the basis of original ephemerides is not correct, whereas the position computed from modified ephemerides is correct (computed coordinates are the same as in Table 2).

5. CONCLUSIONS. The algorithm presented above should allow an off-theshelf receiver to obtain a pseudolite position using only standard navigation message format. It requires only a few simple computations to obtain a proper fixed pseudolite position. Ten parameters from the ephemeris data must be zeroed, a fixed value must be substituted for two parameters and four values must be calculated on the basis of a known pseudolite position. These values will be used to modify the navigation data in a transmitter or in navigation data file for post-processing. Despite the fact that the satellite position computations in a receiver are time-dependent, the algorithm will result in fixed coordinates regardless of the GPS time.

\section{REFERENCES}

Bond, J. (2007). Bringing GPS Into Harsh Environments for Deformation Monitoring. PhD Thesis, University of New Brunswick, Geodesy and Geomatics Engineering.

Cellmer, S. and Rapinski, J. (2010). Linearization problem in pseudolite surveys. Journal of Applied Geodesy, 4, 33:39.

Cobb, H. S. (1997). GPS Pseudolites: Theory, Design and Applications. PhD Thesis, Stanford University.

Lee, H. K., Wang, J., Rizos, C. and Grejner-Brzezinska, D. (2004). Analyzing the Impact of Integrating Pseudolite Observables into a GPS/INS System. Journal of Surveying Engineering, 130:139.

Strang, G. and Borre, K. (1997). Linear Algebra, Geodesy, and GPS. Wellesley-Cambridge Press.

Wang, J. J., Wang, J., Sinclair, D., Watts, L. and Lee, H. K. (2005). Tropospheric Delay Estimation for Pseudolite Positioning. Journal of Global Positioning Systems. Vol. 4, No. 1-2, 106-112.

Wang, J. (2002). Applications of Pseudolites in Positioning and Navigation: Progress and Problems. Journal of Global Positioning Systems, 1(1), 48-56. 